\title{
GAMBARAN KUALITAS HIDUP PASIEN GAGAL GINJAL KRONIS YANG MENJALANI TERAPI HEMODIALISA
}

\author{
Suwanti $^{1}$, Taufikurrahman ${ }^{1}$, Mohamad Imron Rosyidi ${ }^{1}$, Abdul Wakhid ${ }^{1}$ \\ ${ }^{1}$ Fakultas Keperawatan Universitas Ngudi Waluyo \\ abdul.wakhid2010@gmail.com
}

\begin{abstract}
ABSTRAK
Kualitas hidup merupakan keadaan dimana seseorang mendapatkan kepuasan atau kenikmatan dalam kehidupan sehari-hari. Indikator dari kualitas hidup diantaranya yaitu, dimensi kesehatan fisik, dimensi kesejahteran pisikologis, dimensi hubungan sosial, dan dimensi kesehatan lingkungan. Tujuan penelitian untuk mengetahui gambaran kualitas hidup pada pasien gagal ginjal kronis yang menjalani terapi hemodialisa di RSUD Ambarawa. Metode penelitian menggunakan metode deskriptif dengan populasi81 respondendan jumlah sampel 41 responden diambil menggunakan metode accidental sampling. Alat pengambilan data menggunakan skala kualitas hidup dari WHOQOL-BREF. Analisa data menggunakan analisis univariat. Hasil penelitian didapatkan gambaran kualitas hidup pasien gagal ginjal kronik dilihat dari dimensi kesehatan fisik memiliki kualitas hidup buruk, yaitu sebanyak 23 orang $(56,1 \%)$. Dimensi kesehatan psikologi memiliki kualitas hidup buruk, yaitu sebanyak 24 orang $(58,5 \%)$. Dimensi hubungan sosial memiliki kualitas hidup baik, yaitu sebanyak 21 orang (51, $2 \%$ ). Dimensi lingkungan memiliki kualitas hidup baik, yaitu sebanyak 22 orang $(53,7$. Gambaran kualitas hidup pasien gagal ginjal yang menjalani hemodialisa memiliki kualitas hidup buruk sebanyak 25 orang $(61,0 \%)$, sedangkan 16 orang responden $(39,0 \%)$ memiliki kualitas hidupbaik. Keluarga lebih mengetahui pentingnya dukungan dan motivasi keluarga maupun kerabat selama terapi hemodialisa sehingga dapat meningkatkan harapan dan kualitas hidup pasien yang lebih tinggi.
\end{abstract}

Kata kunci: kualitas hidup, gagal ginjal kronik, hemodialisa

\section{DESCRIPTION OF LIFE QUALITY OF THE PATIENTS SUFFERING FROM CHRONIC RENAL FAILURE WHO WENT UNDERHEMODIALYSIS}

\begin{abstract}
Quality of life is a codition where a person gainssatisfaction or enjoyment in everyday life. The indicators of the quality of life, are dimension of physical health, dimension of psychological, social dimension, dimension of environmental health. The aim of the study to knowthe description of life quality of the patients suffering from chronic renal failure who went underhemodialysis inAmbarawa General Hospital. Method of the study used a descriptive method with population 81 respondent and 41 respondents as the samples taken by using accidental sampling method. The data collecting tool used the life quality scale of WHOQOL-BREF. Data analysis used SPSS version 23. O. Finding of the study the description of the quality of life of patients with chronic renal failure seen from the physical health dimension had a poor quality of life, as many as 23 people (56.1\%). Thedimension of psychology health had a poor quality of life, namely as many as 24 people (58.5\%). The dimensions of social relations have a good quality of life, as many at 21 people (51.2\%). The environmental dimension has a good quality of life, as many at 22 people (53.7\%). The description of the quality of life of patients suffering from chronic renal failure undergoing hemodialysis have a poor quality of life of 25 people (61.0\%). It is hoped that the family will be more aware about the importance of family support and motivation during hemodialyisistherapy so that it can improve the quality of life for the patients.
\end{abstract}

Keywords: Quality of life, chronic renal failure, hemodialysis

\section{PENDAHULUAN}

Kualitas hidup merupakan keadaan dimana seseorang mendapatkan kepuasan atau kenikmatan dalam kehidupan sehari-hari. Kualitas hidup tersebut menyangkut kesehatan fisik dan kesehatan mental yang berarti jika seseorang sehat secara fisik dan mental maka orang tersebut akan mencapai suatu kepusan dalam hidupnya. Kesehatan fisik itu dapat dinilai dari fungsi fisik, keterbatasan peran 
fisik, nyeri pada tubuh dan persepsi tentang kesehatan. Kesehatan mental itu sendiri dapat dinilai dari fungsi sosial, dan keterbatasan peran emosional (WHO, 2012). Selain itu indikator dari kualitas hidup diantaranya yaitu, Dimensi kesehatan fisik, Dimensi kesejahteran pisikologis, Dimensi hubungan social, dan Dimensi hubungan dan lingkungan.

Pasien gagal ginjal kronik dalam memperbaiki kualitas hidup sendiri dipengaruhi oleh beberapa faktor antara lain: usia, jenis kelamin, tingakat stadium GGK, frekuensi terapi hemodialisa, dukungan sosial. Faktor tersebut diharapkan pasien agar dapat beradaptasi dan mengatasi perubahan terhadap lingkungan sehingga menjadi sebuah kemampuan koping (Pratiknya, 2010). Kualitas hidup pasien gagal ginjal kronik yang menjalani terapi hemodialisa masih merupakan masalah yang menarik perhatian para profesional kesehatan. Hasil penelitian Ibrahim (2009) menunjukkan bahwa $57.2 \%$ pasien yang menjalani hemodialisa mempersepsikan kualitas hidupnya pada tingkat rendah dengan kondisi fisik merasa kelelahan, kesakitan dan sering gelisah, pada kondisi psikologis pasien tidak memiliki motifasi untuk sembuh, secara hubungan sosial dan lingkungan pasien menarik diri dari aktifitas di masyarakat dan 42, 9\% pada tingkat tinggi. Hasil penelitian tersebut menunjukkan bahwa kualitas hidup penderita GGK dalam tingkat rendah akan tetapi ada hampir dari setengah dari penderita yang tetap mempunyai kulitas hidup dalam kategori tinggi walaupun sedang menjalani terapi hemodialisa.

Prevalensi gagal ginjal kronik menurut United State Renal Data System(USRDDS) pada tahun 2013 adalah sekitar 10-13\% didunia. Berdasarkan data dari Riskesdas pada tahun 2013, prevalensi gagal ginjal kronis $0,2 \%$ dari penduduk Indonesia. Hanya $60 \%$ dari pasien gagal ginjal kronis tersebut yang menjalani terapi dialisis) (Riskesdas, 2013). Berdasakan survei dari Perhimpunan Nefrologi Indonesia (PERNEFRI) pada tahun 2014 menyebutkan bahwa Indonesia merupakan negara dengan prevalensi penyakit gagal ginjal kronik yang cukup tinggi, yaitu sekitar 30, 7 juta penduduk. Prevalensi gagal ginjal kronik berdasarkan data dari Riskesdas pada tahun 2013 jawa tengah menduduki peringkat ke-4 dengan presentase $0,3 \%$. Gagal ginjal kronik, meningkat tajam pada kelompokumur 35-44 tahun (0, 3\%), diikuti umur 45-54 tahun $(0,4 \%)$, dan umur
55-74 tahun $(0,5 \%)$, tertinggi pada kelompok umur $\geq 75$ tahun $(0,6 \%)$. Prevalensi pada lakilaki $(0,3 \%)$ lebih tinggi dari perempuan $(0$, $2 \%$, prevalensilebih tinggi pada masyarakat perdesaan $(0,3 \%)$, tidak bersekolah $(0,4 \%)$, pekerjaan wiraswasta, petani/nelayan/buruh 0 , 3\%. (Riskesdas, 2013)

Di Jawa Tengah pasien yang menderita penyakit Gagal Ginjal Kronik dan menjalani hemodialisa juga terus meningkat. Di Kota Semarang menunjukkan bahwa bulan Maret 2010 sampai Maret tahun 2011 telah dilakukan 5621 tindakan hemodialisa, dengan rata-rata 18 pasien/ hari. Urutan penyebab gagal ginjal pasien hemodialisa dari tahun 2014 masih sama dengan tahun sebelumnya. Penyakit ginjal hipertensi meningkat menjadi $37 \%$ diikutu oleh nefropati diabetika sebanyak $27 \%$ glomerulofati primer memberi proporsi yang cukup tinggi sampai10\% dan nefropati obsktruktif pun masih memberi angka 7\% angka ini cukup tinggi hal ini bisa diminimalkann dengan menambah jenis etiolgi pada IRR. Penyebab kematia terbanyak pada pasien hemodialisa adalah kardiovaskuler (K1) sebanyak 59\% masih cukup banyak penyebab kematian diindonesia diketahui (17\%) karena pasien meninggal diluar rumah sakit (Renal Registry, 2014).

Berdasarkan data yang didapatdari rekam medik RSUD Ambarawa bahwa pasien yang menjalani hemodialisa pada tahun 2014 berjumlah 1.539 orang, pada tahun 2015 berjumlah 1.792 orang, dan pada tahun 2016 berjumlah 2.104 orang. Hal ini membuktikan bahwa yang menjalani hemodialisa di RSUD ambarawa mengalami peningkatan setiap tahunnya. Studi pendahuluan yang dilakukan pada tanggal 14 November 2017. Dari wawancara yang dilakukan kepada 3 pasien yang menjalani hemodialisa didapatkan data mengenaidimensi fisik, dimensi psikologis, dimensi lingkungan, dan dimensi sosial.

Kualitas hidup pada pasien GGK akan mengalami kualitas hidup yang kurang dikarenakan kurangnya kemauan kualitas hidup yang sudah mulai pasrah dengan keadaan penyakitnya. Pada pasien gagal ginjal kronik dalam memperbaiki kualitas hidup sendiri dipengaruhi oleh beberapa faktor antara lain: usia, jenis kelamin, tingakat stadium GGK, frekuensi terapi hemodialisa, dukungan sosial. Faktor tersebut diharapkan pasien agar dapat beradaptasi dan mengatasi perubahan 
terhadap lingkungan sehingga menjadi sebuah kemampuan koping. Tujuan umum penelitian ini adalah untuk mengetahuikualitas hidup pada pasien gagal ginjal kronis yang menjalani terapi hemodialisa

\section{METODE}

Penelitian ini merupakan penelitian Jenis penelitian yang dilakukan adalah penelitian deskriptif. Penelitian ini dilakukan di RSUD AmbarawaKabupaten Semarang pada tanggal 27-29Juni 2018. Jumlah populasi pasien gagal ginjal kronik yang menjalani hemodialisa di Rumah Sakit Ambarawa pada bulan September- November 2017 sejumlah 81 orang. Teknik pengumpulan data dalam penelitian ini menggunakan teknik sampling yang digunakan adalah accidental sampling. Besar sampel yang digunakan sejumlah 41 sampel.Kriteria inklusi dalam penelitian ini adalah pasien gagal ginjal kronik yang menjalani hemodialisa di RS Ambarawa, pasien yang bersedia menjadi responden, pasien yang bisa membaca dan menulis, pasien sudah menikah. Sedangkan kriteria eksklusi dari penelitian ini adalah pasien GGK dengan komplikasi penyakit lain, pasien yang menolak jadi responden, pasien dengan penurunan kesadaran secara mendadak.

Alat pengumpulan data dalam penelitian ini yaitu kuisioner untuk melihat gambaran
Kualitas hidup pada pasien gagal ginjal kronis yang menjalani terapi hemodialisa di RSUD Ambarawa. Untuk mengukur kualitas hidup menggunakan alat ukur (instrumen) kuisioner WHOQoL. Pada penelitian ini, peneliti menggunakan alat ukur terjemahan dari WHOQOL-BREF (2008). Kuesioner tersebut terdiri dari 26 item, yang sudah terbagi dalam 5 aspek yaitu kesehatan fisik, psikologis, hubungan sosial, lingkungan, kualitas hidup. Sebagai alat untuk mengumpulkan data dalam penelitian ini sudah dilakukan uji validitas dan reliabilitas. Kuesioner kualitas hidup WHOQOL-BREF, yaitu kuisioner untuk menilai kualitas hidup yang sudah teruji validitas danreabilitasnya olehSalim, dkk (2007).

Variabel kualitas hidup akan diukur dengan menggunakan skala kualitas hidup dari WHOQOL-BREF (Lopez \& Snyder, 2008). Skala tersebut terdiri dari 26 item, yang sudah terbagi dalam 4 dimensi yaitu kesehatan fisik, psikologis, hubungan sosial, lingkungan, dan kesehatan umum. Pada penelitian ini, peneliti menggunakan alat ukur terjemahan dari WHOQOL-BREF.

\section{HASIL}

Hasil penelitia disajikan sebagai berikut :

Tabel 1.

Karakteristik responden $(n=41)$

\begin{tabular}{lcc}
\hline \multicolumn{1}{c}{ Variabel } & f & $\%$ \\
\hline Jenis Kelamin & & \\
\hline Laki-laki & 28 & 68,3 \\
\hline Perempuan & 13 & 31,7 \\
\hline Usia & 7 & 17,1 \\
\hline Dewasa Akhir (36-45 th) & 13 & 31,7 \\
\hline Lansia Awal (46-55 th) & 13 & 31,7 \\
\hline Lansia Akhir (56-65 th) & 8 & 19,5 \\
\hline Manula (> 65 th) & & \\
\hline Lama Menderita GGK & 22 & 53,7 \\
\hline$<1$ tahun & 9 & 22 \\
\hline $1-2$ Tahun & 10 & 24,4 \\
\hline$>2$ tahun & & \\
\hline
\end{tabular}


Tabel 2

Kualitas Hidup Pasien Gagal Ginjal Kronik Dilihat dari berbagai dimensi ( $\mathrm{n}=41)$

\begin{tabular}{lcc}
\hline \multicolumn{1}{c}{ Variabel } & Frekuensi & Persentase (\%) \\
\hline Dimensi kesehatan fisik & & \\
Buruk & 23 & 56,1 \\
Baik & 18 & 43,9 \\
\hline Dimensi kesehatan psikologis & 24 & 58,5 \\
Buruk & 17 & 41,5 \\
Baik & & \\
\hline Dimensi hubungan sosial & 20 & 48,8 \\
Buruk & 21 & 51,2 \\
Baik & & \\
Dimensi Hubungan Sosial & 19 & 46,3 \\
Buruk & 22 & 53,7 \\
Baik & & 61 \\
Kualitas hidup & 25 & 39 \\
Buruk & 16 & \\
Baik & & \\
\hline
\end{tabular}

\section{PEMBAHASAN}

Berdasarkan hasil pengumpulan data penelitian yang sudah disajikan sebelumnya diatas maka dapat dibahas berdasarkan hasil penelitian.

1. Kualitashidup pasien gagal ginjal kronik dilihat dari dimensi kesehatan fisik

Berdasarkan table tersebut dilihat dari dimensi kesehatan fisik sebagian besar pasien memiliki kualitas hidup buruk, yaitu sejumlah 23 orang $(56,1 \%)$. Hal ini sesuai dengan teori kualitas hidup Menurut WHOQoL(The World Health Organization Quality of Life) (2010), Aktivitas sehari-hari menggambarkan kesulitan dan kemudahan yang dirasakan individu ketika melakukan kegiatan sehari-hari. Ketergantungan pada obat-obatan dan bantuan medis menggambarkan seberapa besar kecenderungan individu dalam menggunakan obat-obatan atau bantuan medis lainnya dalam melakukan aktivitas sehari- hari. Energi dan kelelahan menggambarkan tingkat kemampuan yang dimiliki oleh individu dalam menjalankan aktivitasnya sehari-hari. Sakit dan ketidaknyamanan: menggambarkan sejauh mana perasaan keresahan yang dirasakan individu terhadap hal-hal yang menyebabkan individu merasa sakit. Tidur dan Istirahat menggambarkan kualitas tidur dan istirahat yang dimiliki oleh individu. Kapasitas kerja menggambarkan kemampuan yang dimiliki individu untuk menyelesaikan tugas-tugasnya.

Berdasarkan hasil penelitian diketahui bahwa semua responden dapat melakukan berbagai aktivitas seperti yang disebutkan diatasperlunya terapi medisuntuk dapat berfungsi dalam kehidupan sehari-hari dan untuk mencegah rasa sakit fisik, seperti yang disebutkan oleh (Anggraini, 2016). Hasil penelitian diidapatkan 10 reponden masih kurang memiliki vitalitas yang cukup untuk aktivitas sehari-hari, sebanyak 13 responden biasa saja dalam bergaul, kepuasan dalam tidur biasa saja. Kepuasan dengan kemampuan untuk menampilkan aktivasnya sejumlah 18 responden, kempauan responden untuk bekerja sejumlah 18 respondenbiasa saja.

Kualitas hidup merupakan satu komponen utama yang bersifat subyektif untukkesejahteraan hidup manusia. Komponen dari kualitas hidup salah satunya adalah kepuasan hidup. Kepuasan hidup selalu mengorientasikan diri pada proses pengalaman masa lalu dan masa kini. Kualitas hidup digunakan secara luas sebagai indeks kesejahteraan fisik pada orang-orang lanjut usia(56-65), ada banyak hal yang dapat menciptakan munculnya kepuasan akan hidup pada lansia salah satunya apabila lansia mampu menyelesaikan tugas-tugas perkembangan. Adapun tugas-tugas perkembangan lansia adalah menyesuaikan diri dengan kematian pasangan hidup, membentuk hubungan dengan orang lain yang seusia dan menyesuaikan diri dengan peran sosial (Vicky Tresnia, 2012). Sedangkan kesehatan fisik dalam kategori baik sebanyak 18 orang, kondisi ini dapat disimpulkan bahwa masih banyak responden yang mengalami gangguan 
fisik. Kesehatan fisik terganggu dapat disebabkan oleh beberapa faktor sesuai dengan teori WHOQOL diantaranya adalah aktivitas sehari-hari, energi kelelahan, mobilitas, sulit dan ketidaknyamanan, istirahat tidur, kapsitas pekerjaan.

2. Kualitas hidup pasien gagal ginjal kronik dilihat dari dimensi kesehatan psikologi

Berdasarkan hasil penelitian tersebut, mayoritas responden memiliki kualitas hidup buruk, yaitu sebanyak 24 orang $(58,5 \%)$, didapatkan hasil penelitian didapatkan responden sebagian besar tidak banyak menikmati hidup dari pertanyaan no 5 yakni respondden mempunyai kualitas hidup dalam kategori buruk yakni sebnyak 13 responden. Kuesioner no 6 sebanyak 14 responden sedikit merasa hidupnya berarti, kuisioner no 7 sebanyak 13 responden kurang mampu berkonsentrasi, kuisioner no 11 sebnyak 8 responden sedikit menerima penampilan tubuhnya, kuisioner no 19 senbanyak 14 responden tidak puas terhadap dirinya, kuisioner no 26 sebanyak 11 responden sering memiliki perasaan negative (feeling blue).

Menilai kualitas hidup yang termasuk dalam kategori buruk yaitu dimensi psikologis dimana sebagian besar responden menjawab pertanyaan kuesioner yang diberikan oleh peneliti kepada responden dengan hasil jawaban responden didapatkan data bahwa sebagian besar responden mampu berkonsentrasi sedang $(41,4 \%)$, responden tidak menerima penampilan tubuh $(12,1 \%)$, responden puas terhadap diri sedang $(46,3 \%)$. Hasil penelitan ini Inshan Marta (2017) menyatakan bahwa mereka merasakan bahwa kepuasan hidup biasa saja $(39,7 \%)$, responden tidak menikmati hidup $(27,6 \%)$, merasa hidupnya kurang berarti $(58,6 \%)$, responden juga tidak mampu berkonsentrasi maksimal (34,5\%), responden tidak punya cukup uang untuk memenuhi kebutuhan (46,6\%), responden merasa kesepian, putus asa, cemas, dan depresi $(36,2 \%)$ dan responden merasa tidak puas dengan kehidupan seksual $(74,1 \%)$. Sedangkan kesehatan psikologi dalam kategori baik sejumlah 17 orang (41,5\%). Menilai kualitas hidup baik yang termasuk dalam kategori baik yaitu dimensi psikologi dimana sebagian besar responden menjawab pertanyaan kuisioner yang diberikan oleh peneliti kepada responden dengan hasil jawaban responden didapatkan data bahwa sebagian besar responden menyatakan bahwa responden mampu berkonsentrasi sedang $(41,4 \%)$.

Pasien yang sudah lama menjalani hemodialisis cenderung memersepsikan kualitas hidupnya semakin menurun. Kualitas hidup yang menurun ini juga dapat di kaitkan dengan perubahan kehidupan ekonomi dikarenakan tingginya biaya yang harus dikeluarkan untuk satu kali proses hemodialisis. Hal inilah yang sering kali dirasakan dapat membebani penderita dan keluarganya, ketergantungan pada mesin hemodialisis, juga membuat aktivitas penderita menjadi terbatas serta penurunan kodisi kesehatan fisik dan psikososial dari waktu kewaktu.

3. Kualitas hidup pasien gagal ginjal kronik dilihat dari dimensi hubungan sosial

Berdasarkan hasil penelitian, mayoritas responden memiliki kualitas hidup baik dari dimensi hubungan sosialnya, yaitu sebanyak 20 orang $(48,8 \%)$. Keadaan ini juga berhubungan dengan masalah ketidakpuasan dalam kehidupan seksual, terutama responden laki-laki yang dalam penelitian ini lebih banyak (68,3\%) dari wanita $(31,7 \%)$. Kuisioner no 20 responden ssebnayak 10 menyatakan tidak puas dengan hubungan sosialnya, kuisioner no 21 responden sebanyak 21 responden sebanyak 9 menyatakan kepuasan dengan kehidupan seksual biasa saja. Kualitas hidup pada dimensi social sebelum menjalani hemodialisa tergantung dari dukungan social yang diterima oelh responden. Baik dukungan emosiaonal dari keluarga dan kelompok social dilingkungan responden, juga dukungan instrumental dan informasional

Hasil penelitian ini sesuai dengan pendapat Hudak \& Gallo (2010) yang mengatakan bahwa pasien yang menjalani HD akan terjadi penurunan fungsi seksual (libido) pada lakilaki: sering terjadi impotensi, mungkin karena penyakitnya atau efek samping dari obat-obat anti hipertensi. Pada wanita selama proses hemodialisis tidak mengalami proses menstruasi karena pengaruh obat imunosupresi. Hasil penelitian ini sesuai hasil penelitian Martono (2006) bahwa keluarga memiliki tuntutan lebih kuat dibandingkan tenaga medis karena hubungan kekerabatannya. Walau pun tenaga medis merasa bahwa pasien membutuhkan dukungan sosial yang banyak, akan tetapi tenaga medis mempunyai keterbatasan. Keterbatasan ini 
dapat berupa etika profesi yang tidak memungkinkan tenaga medis terlibat jauh dalam urusan pribadi pasiennya kecuali yang berhubungan dengan penyakitnya. Keterbatasan lain karena banyaknya pasien yang harus ditangani sehingga tenaga medis mengandalkan partisipasi aktif dari keluarga. jalani terapi hemodialysis secara tidak langsung dapat memotivasi pasien untuk menjadi lebih baik. Dari hasil pengamatan peneliti selamaa melakukan penelitian tampak adanya hubungan baik anatara pasien dengan teman pasien. Beberapa responden mengatakan dukungan yang diberikan teman membuat pasien menjadi lebih semnagat untuk menjalani hemodialysis dan termotivasi untuk bisa sembuh dari penyakitnya.

Hal tersebut menunjukkan masih kurangnya perhatian dan dukungan teman terhadap setiap kegiatan yang pasien gagal ginjal kronis ikuti dengan memberikan arahan dan informasi yang benar terhadap kegiatan-kegiatan tersebut. Hal tersebut menjadikan pasien belum mendapatkan apa yang dibutuhkan oleh mereka sehingga mereka kurang merasa berharga dalam menjalani kehidupan mereka. Informasi-informasi yang diberikan orang lain akan mempengaruhi seseorang untuk menambah pengetahuan, kemampuan, dan keterampilan sehingga akan membuat keyakinan untuk melakukan sesuatu menjadi besar (Sarafino, 2014).

4. Kualitas hidup kesehatan umum pasien gagal ginjal kronik dilihat dari dimensi lingkungan

Berdasarkan hasil penelitian, mayoritas responden memiliki kualitas hidup baik dari dimensi lingkungan, yaitu sebanyak 22 orang $(53,7 \%)$, sedangkan 19 orang responden $(46,3 \%)$ memiliki kualitas hidup yang buruk dari dimensi lingkuungan. Responden merasa bahwa keberadaannya di tempat mereka tinggal dan bekerja sudah kurang dibutuhkan, responden tidak bekerja. Responden dianggap tidak mempunyai kemampuan untuk beraktifitas juga dalam hal berpendapat. Responden jarang dimintai pendapat dan jarang dilibatkan dalam pembuatan keputusan. Peneliti menilai ini ada hubungannya dengan jumlah responden laki-laki yang lebih banyak, karena dalam kehidupan rumah tangga mereka menjadi kepala keluarga yang seharusnya lebih banyak terlibat dalam membuat keputusan. Hal ini terjadi juga karena karakteristik responden laki-laki yang membutuhkan informasi lebih banyak dan responden wanita lebih sering berkonsultasi kepada tenaga medis. Ini sesuai yang dijelaskan Safarino dalam Martono (2010) bahwa untuk mengatasi masalah yang dirasakannya, maka laki-laki cenderung mencari informasi lebih banyak agar ia lebih dapat mengenali dan kemudian mencari jalan keluar dari masalah.

5. Kualitas hidup pasien gagal ginjal kronik yang menjalani hemodialisa

Berdasarkan hasil penelitian, diketahui bahwa paling banyak responden dengan kualitas hidup dalam kategori buruk yaitu sebanyak 25 responden $(61,0 \%)$. Pada kuesioner no 8 didapatkan 11 responden menyatakan sedikit merasa nyaman terhadap kehidupan seharihari, kuesioner no 9 didapatkan 10 responden menyatakan lingkungan tempat tinggalnya lumayan sehat, kuesioner no 12 didapatkan 8 responden menyatakan memiliki cukup uang dalam jumlah sedang, kuesioner no 13 didapatkan 10respoonden menyatakan sedikitnya ketersediaan informasi yang didapatkan, kuesioner no 14 didapatkan 8 responden menyatakan sedikit mendapatkan kesempatn untuk rekeasi dengan keluarga, kuesioner no 23 didapatkan 13 responden menyatakan puas dengan kondisi tempat tinggalnya, kuesioner no 24 didapatkan 10 responden menyatakan puas dengan akses pelayanan kesehatan, kuesioner no 25 didapatkan 10 responden puas dengan ketersediaan transportasi yang digunakan.

Hal tersebut dapat dilihat dari hasil jawaban kuesioner yang diberikan peneliti kepada responden tentang kualitas hidup responden yang terbagi menjadi beberapa kriteria yaitu kualitas hidup dilihat dari segi kesehatan fisik, kesehatan psikologis, dan pengaruh dimensi lingkungan terhadap kualitas hidup responden. Kualitas hidup pasien GGK yang menjalani hemodialisa dipengaruhi oleh faktor-faktor yaitu karakteristik pasien, terapi hemodialisa yang dijalani, status kesehatan pasien seperti kondisi ada tidaknya anemia, juga ada tidaknya depresi, dan faktor terakhir yaitu dukungan keluarga (Septiwi, 2010).

Menilai kualitas hidup yang termasuk dalam kategori baik yaitu dimensi lingkungan dimana sebagian besar responden menjawab pertanyaan kuesioner yang diberikan oleh peneliti kepada responden dengan hasil jawaban responden didapatkan data bahwa sebagian besar responden menyatakan bahwa 
responden mengatakan lingkungan di sekitar tempat tinggal kesehatan dalam jumlah sedang $(41,4 \%)$, masih sedikit ketersediaan informasi bagi kehidupan sehari-hari $(26,9 \%)$, responden kondisi tempat tinggalnya biasa saja $(29,2 \%)$, selain itu responden tidak merasa puas dengan akses layanan kesehatan $(48,3 \%)$. Beberapa indikator tersebut menunjukkan bahwa sebagian besar responden dalam penelitian ini mempunyai kualitas hidup dalam kategori kurang.

Hasil penelitian sejalan dengan hasil penelitian Ibrahim (2009), menunjukan bahwa 57,1\% pasien yang menjalani hemodialisis mempersepsikan kualitas hidupnya pada tingkat rendah dengan kondisi fisik merasa kelelahan, kesakitan dan sering gelisah. Pada kondisi psikologis pasien tidak memiliki motivasi untuk sembuh, secara hubungansosial dan lingkungan pasien menarik diri dari aktifitas dimasyarakat sementara pasien yang menjalani hemodialisis mempersepsikan kualitas hidupnyapada tingkat tinggi dengan kondisi dapat tidur dan istirahat dengan nyaman tidak merasa gelisah dan tidak mudah kelelahan.

\section{SIMPULAN DAN SARAN}

\section{Simpulan}

1. Gambaran kualitashidup pasien gagal ginjal kronik dilihat dari dimensi kesehatan fisik memiliki kualitas hidup buruk, yaitu sebanyak 26 orang $(63,4 \%)$, sedangkan 15 orang responden $(36,6 \%)$ memiliki kualitas hidup yang baik.

2. Gambaran kualitas hidup pasien gagal ginjal kronik dilihat dari dimensi kesehatan psikologi memiliki kualitas hidup buruk, yaitu sebanyak 24 orang $(58,5 \%)$, sedangkan 17 orang responden $(41,5 \%)$ memiliki kualitas hidup yang baik.

3. Gambaran kualitas hidup pasien gagal ginjal kronik dilihat dari dimensi hubungan social memiliki kualitas hidup baik, yaitu sebanyak 21 orang $(51,2 \%)$, sedangkan 20 orang responden $(48,8 \%)$ memiliki kualitas hidup yang buruk.

4. Gambaran kualitas hidup pasien gagal ginjal kronik dilihat dari dimensi lingkungan memiliki kualitas hidup baik, yaitu sebanyak 22 orang $(53,7 \%)$, sedangkan 19 orang responden $(46,3 \%)$ memiliki kualitas hidup yang buruk.
5. Gambaran kualitas hidup pasien gagal ginjal kronik yang menjalani hemodialisa memiliki kualitas hidup buruk sebanyak 25 orang $(61,0 \%)$, sedangkan 16 orang responden $(39,0 \%)$ memiliki kualitas hidup yang baik.

\section{Saran}

1. Bagi Pendidikan Keperawatan

Diharapkan agar bisa menambahkan materi dan SOP pendidikan kesehatan kualitas hidup pasien gagal ginjal kronik kedalam materi perkuliahan. Dan memberikan informasi tambahan bagi pendidikan keperawatan khususnya keperawatan keluarga dalam hal meningkatkan kualitas hidup gagal ginjal kronik yang menjalani terapi hemodialisa.

\section{Bagi Penelitian Selanjutnya}

Peneliti selanjutnya diharapkan dapat meneliti dan mengendalikan faktor yang mempengaruhi kualitas hidup pasien gagal ginjal kronis seperti faktor usia, jenis kelamin, nutrisi, dan faktor lama menjalani hemodialisa.

\section{Bagi praktik keperawatan}

Praktek keperawatan agar dapat meningkatkan pelayanan yang lebih maksimal dan hendaknya perawat menyusun SOP tentang pendidikan kesehatan perawatan keluarga dan mengaplikasikan family suportpada pasien gagal ginjal kronik dalam meningkatkan kualitas hidup.

\section{DAFTAR PUSTAKA}

Anggraini, Y. D. (2016), Kualitas Hidup Pasien Gagal Ginjal Kronis yangMenjalani Hemodialisis Di RSUD Blambangan Banyuwangi. Universitas Jember.

Desita. (2010). Pengaruh Dukungan Keluarga Terhadap Peningkatan KualitasHidup Pasien Gagal Ginjal Kronik yang Menjalani Hemodialisa di RSUPHAM Medan. USU repository.

ESRD. (2012), End Stage Renal Disease (ESRD) Patients in 2012 A Global Perspective. Germany: Fresenius Medical Care. 
Farida, A. 2010. Pengalaman Klien Hemodialisis Terhadap Kualitas Hidup dalam Konteks Asuhan Keperawatan di RSUP Fatmawati Jakarta. Tidak Dipublikasikan.

Ibrahim, K, 2005. Kualitas Hidup pada Pasien Gagal Ginjal Kronik yang Menjalani Hemodialisis. http://www. mkb. online

Indonesian Renal Registry. 2012. 5th Annual Report of Indonesia. http://www. pernefriinasn. org/Laporan/5th\%20Annual\%20Report $\% 20$ Of\%20IRR\%202012. pdf. [3 Desember 2015].

Jumaih, 2011. A Study of Quality of Life and its Determinants among Hemodialysis Patients Using the KDQOL-SF Instrument in One Center in Saudi Arabia. [serial online]

Mardyaningsih, D. 2014. Kualitas Hidup Pada Penderita Gagal Ginjal Kronik yang Menjalani Terapi Hemodialisis di RSUD dr. Soediran Mangun Sumarso Kabupaten Wonogiri. [serial online].

Nurchayati, S. 2010. Analisis Faktor-Faktor yang Berhubungan dengan Kualitas Hidup Pasien Penyakit Ginjal Kronik yang Menjalani Hemodilalisis di Rumah Sakit Islam Fatimah Cilacap dan Rumah Sakit Umum Daerah Banyumas. Tesis. Depok: Universitas Indonesia.

NKF-KDOQI, 2013. Clinical Practice Guidelines on Hypertension and Antihypertensive Agents in Chronic Kidney Disease, Guideline 12.

Patricia et. al. (2011). Keperawatan Kritis: Pendekatan Asuhan Holistik (Edisi 8), Volume dua. Jakarta: EGC.

Price dan Wilson. 2005. Patofisiologi Konsep Klinis Proses -Proses Penyakit. Jakarta: EGC: 912 -980. Rohmawati, E. 2011. Perbedaan Kualitas Hidup Antara Lansia yang Aktif dan yang Tidak Aktif Melakukan Kunjungan ke Posyandu. Tidak Dipublikasikan. Skripsi.

Jember: Fakultas Kesehatan Masyarakat Universitas Jember.

Riset Kesehatan Dasar (Riskesdas) 20013. Jakarta: Badan Penelitian dan Pengembangan Kesehatan Departemen.
Sarafino, E. P. (2008). Health Psychology: Biopsychosocial Interaction. (2nd Ed). New York: John Willey \& Sons Inc.

Smeltzer dan Bare. 2001. Buku Ajar Keperawatan Medikal Bedah Vol 2 Edisi 8. Jakarta: EGC: 1398-1401.

Sudoyo, A, Setiyohadi, B. , Alwi, I. , Simadibrata, M. , dan Setiati, S. 2009. Buku Ajar Ilmu Penyakit Dalam Edisi Kelima Jilid II. Jakarta: Iterna Publising: 1036.

Surjono, A. 2005. Vade-Mecum Pediatri. Jakarta: EGC: 83 United States Renal Data System. 2014. USRDS Annual Data Report Volume 2: End Stage Renal Disease.

Tallis, K. (2005), How to improve the quality of life in patients living with end stage renal failure. Renal Nursing Society of Australian Journal. Vol. 1, No. 1.

Yuliaw. 2009. Hubungan Karakteristik Individu dengan Kualitas Hidup Dimensi Fisik pasien Gagal Ginjal Kronis di RS Dr. Kariadi Semarang. [serial online]

WHO, 2008. How Can We Achieve Global Equity in Provision of Renal Replacement Therapy. Bull. WHO. 86: 161-240

WHOQL-100, WHOQL-BREF and CAWHOQL INSTRUMENTS; user manual and interpretasion guide. Juli 15, 2016 